\title{
Broad and narrow personality traits as markers of one-time and repeated suicide attempts: A population-based study Jelena Brezo ${ }^{1}$, Joel Paris ${ }^{2}$, Martine Hébert ${ }^{4}$, Frank Vitaro ${ }^{3}$, Richard Tremblay ${ }^{3}$ and Gustavo Turecki*1,2
}

\author{
Address: ${ }^{1}$ McGill Group for Suicide Studies, Douglas Hospital Research Center, Montreal, Canada, ${ }^{2}$ Department of Psychiatry, McGill University, \\ Montreal, Canada, ${ }^{3}$ GRIP, University of Montreal, Montreal, Canada and ${ }^{4}$ Department of Sexology, University of Quebec, Montreal, Canada \\ Email: Jelena Brezo - jelena.brezo@mail.mcgill.ca; Joel Paris - joel.paris@mcgill.ca; Martine Hébert - hebertm@uqam.ca; \\ Frank Vitaro - frank.vitaro@umontreal.ca; Richard Tremblay - tremblar@grip.umontreal.ca; Gustavo Turecki* - gustavo.turecki@mcgill.ca \\ * Corresponding author
}

Published: 6 March 2008

BMC Psychiatry 2008, 8:15 doi:10.1186/147/-244X-8-15
Received: II September 2007

Accepted: 6 March 2008

This article is available from: http://www.biomedcentral.com/l47/-244X/8/15

(C) 2008 Brezo et al; licensee BioMed Central Ltd.

This is an Open Access article distributed under the terms of the Creative Commons Attribution License (http://creativecommons.org/licenses/by/2.0), which permits unrestricted use, distribution, and reproduction in any medium, provided the original work is properly cited.

\begin{abstract}
Background: Studying personality traits with the potential to differentiate between individuals engaging in suicide attempts of different degrees of severity could help us to understand the processes underlying the link of personality and nonfatal suicidal behaviours and to identify at-risk groups. One approach may be to examine whether narrow, i.e., lower-order personality traits may be more useful than their underlying, broad personality trait dimensions.
\end{abstract}

Methods: We investigated qualitative and quantitative differences in broad and narrow personality traits between one-time and repeated suicide attempters in a longitudinal, population-based sample of young French Canadian adults using two multivariate regression models.

Results: One broad (Compulsivity: $O R=2.0 ; 95 \% \mathrm{Cl} \mathrm{I.2-3.5)} \mathrm{and} \mathrm{one} \mathrm{narrow} \mathrm{personality} \mathrm{trait}$ (anxiousness: OR $=1.1 ; 95 \% \mathrm{Cl} \mathrm{I.0I-I.I)} \mathrm{differentiated} \mathrm{between} \mathrm{individuals} \mathrm{with} \mathrm{histories} \mathrm{of}$ repeated and one-time suicide attempts. Affective instability $[(\mathrm{OR}=1.1 ; 95 \% \mathrm{Cl} 1.04-\mathrm{I} . \mathrm{I})]$ and anxiousness $[(\mathrm{OR}=.92 ; 95 \% \mathrm{Cl} .88-.95)]$, on the other hand, differentiated between nonattempters and one-time suicide attempters.

Conclusion: Emotional and cognitive dysregulation and associated behavioural manifestations may be associated with suicide attempts of different severity. While findings associated with narrow traits may be easier to interpret and link to existing sociobiological theories, larger effect sizes associated with broad traits such as Compulsivity may be better suited to objectives with a more clinical focus.

\section{Background}

Personality traits may be of value as correlates $[1,2]$, predictors [3], endophenotypes $[4,5]$, and targets of health interventions in the context of a number of psychiatric phenotypes [6,7], including suicidality. There is a growing recognition that the extent of involvement of personality traits with such phenotypes may depend on the position that these traits occupy in personality hierarchy. A distinction has been made between the more specific levels of personality structure, consisting of narrow or lower-order personality traits, and the higher-order, broader dimensions to which they contribute $[8,9]$. 
In an ongoing debate on the merits of these two personality levels, it has been recognized that narrow personality traits $[10,11]$ allow higher predictive accuracy and a better understanding of the relevant etiological mechanisms [12]. This is, in part, because broad personality traits consist only of shared variance of contributing narrow personality traits, while the latter also have unique variance that may be of relevance to some risk behaviours $[10,13]$. Consequently, an association between an outcome and a narrow personality trait may occur even in the absence of a similar association with a related, broad personality trait [12]. Nevertheless, broad personality factors may have greater "bandwidth" and be easier to measure in some cases [13].

When it comes to suicide attempts, an important antecedent of suicide completions $[14,15]$, personality traits may be involved in a dosage-dependent fashion, correlating positively with phenotypic severity [16]. Namely, individuals with histories of repeated suicide attempts may also have more extreme personality profiles than individuals who have attempted only once. Nevertheless, despite the clinical importance of understanding repeated suicide attempts, research on the associated risk factors is still scarce $[16,17]$, especially when it comes to the evidence concerning personality traits. In general, suicide attempters have been observed to have higher levels of aggression, anxiety, neuroticism, extroversion, impulsivity, and psychoticism [1]. In an earlier study in the same sample [18], focusing on suicide attempters as a group, we examined narrow personality trait correlates of previous suicide attempts and of current, serious suicidal ideation. We found small, although significant, contribution of an externalizing personality trait of conduct problems to both of these suicidal phenotypes.

While studies focusing on suicide attempters are useful, they cannot indicate whether there are specific personality traits that may serve as markers of possibly distinct subpopulations of suicide attempters [16], such as one-time and repeated suicide attempters, for example. Using a comparative approach, we investigated qualitative and quantitative differences between broad and narrow personality trait correlates of repeated and one-time suicide attempt histories. We operationalized qualitative differences as those encompassing traits that are dysregulated in selected subgroups of suicide attempters; Quantitative differences, on the other hand, would pertain to traits that are dysregulated across suicide attempter subgroups although, possibly, to a somewhat different extent. We assessed two levels of personality traits (17 narrow and 4 broad personality dimensions) using the Diagnostic Assessment of Personality Pathology-Basic Questionnaire (DAPP-BQ), an instrument with satisfactory psychometric properties $[19,20]$. Analyses were conducted in a sizable, longitudinal, population-based sample of young French Canadian adults. On the basis of previous evidence, we hypothesized that three broad DAPP-BQ dimensionsEmotional Dysregulation $[16,21,22]$, Dissocial Behavior [23]; and Inhibition [24,25], and associated narrow traits, will be highest in our multiple suicide attempters relative to one-time attempters and nonattempters.

\section{Methods \\ Study participants and data collection}

Our sample consisted of 21-24 year-old adults. These individuals have been followed since their last kindergarten year in one of the French-speaking public schools in Quebec $[26,27]$. The total initial sample comprised 957 boys and 946 girls randomly selected to represent urban and rural Quebec. To reduce cultural heterogeneity, only children whose parents were born in Canada and whose mother tongue was French were included in this cohort. The majority of children (89\%) were non-Hispanic Whites. The remainder reported being of Native Indian, Asian, Black, and White Hispanic origin. Only participants who had provided complete data on our personality measures in adulthood $(\mathrm{n}=1094)$ were included. The remainder provided incomplete questionnaire data $(\mathrm{n}=$ $59)$; were disabled, or died by suicide or from other causes $(\mathrm{n}=13)$; could not be $(\mathrm{n}=12)$ or were never contacted ( $\mathrm{n}$ $=11)$; could not be traced $(\mathrm{n}=99)$; refused to participate ( $\mathrm{n}=196)$; lived in a remote area (18); or were missing for unknown reasons $(n=498)$.

The data were obtained using a combination of interviews and self-reports. The study was approved by the research ethics boards of the University of Montreal and McGill University. Written informed consent was obtained from all subjects.

\section{Instruments}

\section{Sociodemographic factors in childhood and adulthood}

Family circumstances surrounding participants as children, consisting of various indices of parental sociodemographic status and living arrangements, were obtained yearly from 6 to 12 years of age.

\section{Traumatic events \\ a. Childhood physical violence (Revised Conflict Tactics Scales) [28,29]}

Using self-reports on 32 questions, this scale assesses childhood incidences of nonviolent discipline, psychological aggression, and physical assault in parent-child and other family relationships. In this study, we selected 14 questions dealing with severe and very severe physical aggression, abuse, and injuries perpetrated by each parent (biological, adaptive, or any person in a parental role) against the respondent as a child. 


\section{b. Childhood sexual violence [30,31]}

This instrument measures incidences of sexual violence since birth up to the age of 18 . Questions ask about abusive sexual acts involving some degree of physical contact (fondling or sexual - vaginal, anal, or oral - relationship imposed by threats or use of force) and perpetrated by immediate family members, school peers/personnel, short/long-term romantic acquaintances, or strangers.

\section{c. Physical partner violence (Revised Conflict Tactics Scales) [29]} Using self-reports, this scale assesses incidences of psychological and physical aggression, sexual coercion, and physical injuries. In order to assess violence perpetrated by the current or partners of the previous five years against the respondent, we selected 11 questions inquiring about acts of severe and very severe aggression and injuries.

\section{d. Yearly calendars - stressful life events}

Using yearly calendars, participants were also asked about atypical/severe stressful events related to finances, school or work, death of a close person, illness or serious injury to self or others, parental separation/divorce, partner/children difficulties, and "other" sources of stress. Most stress items were adapted from an existing instrument [32].

\section{Psychiatric diagnoses}

a. Diagnostic Interview Schedule for adults and children [33]

Psychiatric diagnoses in this study were based on DIS interviews using DSM-III-R criteria. In terms of adult diagnoses, in both mothers and participants, we focused on substance abuse/dependence involving drugs, alcohol, and nicotine; major depressive episodes, mania, and dysthymia; generalized anxiety, panic and phobias. Substance misuse phenotypes were considered individually and mood and anxiety disorders as groups in both adolescence and adulthood. Adolescent diagnoses were assessed using parental and self-reports and similarly grouped into disruptive (attention-deficit-hyperactivity, oppositionaldefiant, and conduct disorders), anxiety (simple and social phobias, separation anxiety, panic, avoidant, overanxious, and generalized anxiety disorder), and mood disorders (major depression and dysthymia). Fifty interviewers interviewed the subjects around, on average, 15.7 and 21.4 years of age.

\section{Personality traits \\ a. Diagnostic Assessment of Personality Pathology-Basic Questionnaire (DAPP-BQ) [19,34]}

This two-hundred-ninety-question scale measures 69 specific, 18 basic, and 4 broad personality traits. The eighteen subscales consist of 12 to 16 questions about general personal preferences and behaviors. Internal consistency coefficients of those personality traits that were used in this study were acceptable (83-93).

\section{b. Barratt Impulsiveness Scale [35]}

This is a 30-item self-report instrument assessing trait impulsivity and referring to the general ways in which a person acts or thinks in different situations. The internal consistency in BIS-10, the version used in this study, was acceptable $(\alpha=.81)$.

\section{Suicidality}

a. Violence of the method

Hanging, jumping from a high place, shooting a firearm, cutting, burning, and jumping under a vehicle were classified as violent suicide attempts. Non-violent methods encompassed drug overdose, drowning, carbon monoxide poisoning, and induction of hypothermia through the use of alcohol and neuroleptic drugs [36].

\section{b. Scale for Suicidal Ideation [37,38]}

This 19-item self-report scale consists of four sections measuring current attitudes toward living and dying, characteristics of suicidal ideation, and actualization of contemplated attempt. The previously reported scale reliability varied between .89 and 92. Our Cronbach alpha was .63.

c. Suicide Intent Scale (SIN) [39]

This 20-question scale is administered to self-reported suicide attempters and designed to assess the "intensity" of the wish to die during their most recent attempt by measuring thoughts and feelings and objective circumstances at that time. Alpha coefficient in the present study was .64.

\section{d. Suicide attempts (lifetime)}

A three-level outcome variable, classifying individuals into non-attempters, one-time and multiple suicide attempters, was created using information extracted from several scales and at two assessment waves:

i) Early adulthood:

-"Have you already attempted suicide?" (SIN)

-"How many attempts have you made prior to the one in question?" (SIN)

ii) Midadolescence

The presence and frequency of suicide attempts over lifetime and six-months were assessed using parental and adolescent responses to three questions originating in DISC-2 scales, designed to screen for depressive symptomatology:

-"Have you already attempted suicide?"

-"How many times?" 
-"Have you attempted suicide during the last 6 months?"

\section{e. Suicidal ideation (lifetime)}

A three-level outcome variable was created using information extracted from three different scales in adolescence and early adulthood, with suicidal ideas being reported once classified as transient and those reported on at least two occasions as persistent.

\section{Social support}

a. Social Support Scale [40]

This instrument measures perceived support by friends and family using fifteen statements. Item response levels range from 'not at all like me' to 'a lot like me'. Cronbach alpha was .88.

\section{Statistical procedures and analytical approach}

Identification of the correlates of suicide attempts proceeded in several steps. We began with univariate analyses (ANOVAs, Scheffe Multiple Comparison, and Chi square tests) to pre-select variables for inclusion in multivariate analyses, focusing on several domains previously shown to be associated with our outcomes of interest: sociodemographic (parental socioeconomic status, education and ages at birth of first child, gender, and participants' adult income), psychiatric (adolescent and adult Axis I disorders), experiential (physical and sexual abuse, social support, stressful events), and 17 narrow and 4 broad personality traits.

We adhered to the model-building logistic regression protocol outlined by Hosmer \& Lemeshow [41]. Significant main effects within each domain of risk factors were identified in a series of hierarchical regression analyses, beginning with the univariately-significant demographic variables. Multinomial logistic regression was used to identify the best model for a three-level outcome ("2" = repeated suicide attempters, "1" = one-time suicide attempters; "0" = non-attempters). We built two multinomial models, using either broad or narrow personality traits, along with the univariately-significant variables from other risk domains. Each model was adjusted for a possible confounding effect of the childhood mood disorder as it was not completely independent of the response variable (see Methods, Suicidality subsection).

We compared the two models' overall success in identifying correlates of one-time and repeated suicide attempts using Bayesian $(\mathrm{BIC}=-2 \mathrm{LL}+\ln (\mathrm{N}) \times \mathrm{k})$ and Aikaike Information Criteria ( $\mathrm{AIC}=-2 \mathrm{LL}+2 \times \mathrm{k}$ ), where $\mathrm{N}$ stands for sample size, ln for natural logarithm, $\mathrm{k}$ for number of parameters, and LL for log likelihood.

Weighted analyses were adjusted by the inverse of the participant's probability to be missing on the outcome. This probability was conditioned on family's socioeconomic status and participant's gender- variables that were related to attrition in our cohort. Since weighted analyses yielded similar results to our unweighted analyses, only the former are presented.

\section{Results \\ Univariate and descriptive statistics (Table I; Figures I and 2)}

Figure 1 shows narrow personality traits scores to be the highest in repeated suicide attempters. The exceptions were scores in three of these traits: compulsivity, rejection and restricted expression (Table 1). ANOVA-based analyses demonstrated significant differences between the three subgroups in 13 narrow personality traits at $\mathrm{p}=.05$ level and in 9 of them at Bonferroni-corrected $\mathrm{p}$ value $(\mathrm{p}=.002$; 21 tests): [anxiousness (F2,897 = 17.42; p = .0005), submissiveness $(\mathrm{F} 2,897=7.20 ; \mathrm{p}=.001)$, suspiciousness $(\mathrm{F} 2,897=11.27 ; \mathrm{p}=.0005)$, cognitive-perceptive dysregulation $(\mathrm{F} 2,897=27.71 ; \mathrm{p}=.0005)$, insecure attachment $(\mathrm{F} 2,897=18.58 ; \mathrm{p}=.0005)$, conduct problems $(\mathrm{F} 2,897=$ 14.97; $\mathrm{p}=.0005)$, affective instability $(\mathrm{F} 2,897=29.74 ; \mathrm{p}$ $=.0005)$, identity problems $(\mathrm{F} 2,897=17.71 ; \mathrm{p}=.0005)$, and passive aggressivity $(\mathrm{F} 2,897=8.11 ; \mathrm{p}=.0005)]$. The Scheffe multiple comparison test identified several narrow traits differentiating between repeated suicide attempters and the remaining two groups (submissiveness, cognitive-perceptive dysregulation, insecure, suspiciousness, and anxiousness); between suicide attempters and nonattempters (conduct problems and passive aggressivity), and among all three groups (affective instability and identity problems).

Broad personality trait profiles were quite different across nonattempters, first-time attempters and repeaters (Figure 2). ANOVA tests showed significant differences in three of these traits: Emotional Dysregulation $\left(\mathrm{F}_{2,897}=21.51 ; \mathrm{p}=\right.$ $.0005)$, which also differentiated between repeated suicide attempters and the remaining two groups (Table 1), Dissocial Behavior $\left(\mathrm{F}_{2,897}=7.26 ; \mathrm{p}=.001\right)$, and Compulsivity $\left(\mathrm{F}_{2,897}=3.70 ; \mathrm{p}=.025\right)$. Overall, variability in scores among nonattempters was very low (Figure 2 ). Nonattempters also had lower Emotional Dysregulation and Dissocial Behavior than both groups of suicide attempters. Relative to nonattempters, Compulsivity and Inhibition scores were higher in repeated and lower in one-time suicide attempters. Repeated suicide attempters had the highest levels of all four broad personality factors (Figure 2).

\section{Multivariate statistics: multinomial regression models (Tables 2 and 3)}

In the first model, which featured broad personality traits, Compulsivity was the only significant correlate, differentiating between repeated and one-time suicide attempters 
Table I: Univariate personality trait differences between nonattempters, one-time and repeated suicide attempters

\begin{tabular}{|c|c|c|c|c|c|c|}
\hline & \multicolumn{2}{|c|}{ Nonattempters (NSA) } & \multicolumn{2}{|c|}{ One-time Attempters (SA) } & \multicolumn{2}{|c|}{ Repeated Attempters (RSA) } \\
\hline & Mean & SD & Mean & SD & Mean & SD \\
\hline Emotional Dysregulation & $-.07 \mathrm{~b} * * *$ & .98 & .18 c*** & .95 & $1.07^{b^{* * * * *} \mathrm{c}^{* * * * *}}$ & 1.08 \\
\hline Dissocial Behavior & $-.03^{b^{* *}}$ & .99 & .23 & 1.10 & $.58^{\mathrm{b}^{* * *}}$ & 1.27 \\
\hline Inhibition & -.01 & .97 & -.10 & 1.15 & .07 & 1.12 \\
\hline Compulsivity & $-\left..0\right|^{a \&}$ & 1.01 & $-.30^{a \& c \&}$ & .94 & $.19 c \&$ & .94 \\
\hline Affective instability & $40.33^{\mathrm{a}^{* * * *} \mathrm{~b}^{* * * *}}$ & 11.85 & $46.45^{\mathrm{a} * * * * * *}$ & 12.08 & $55.00^{b^{* * *}} \mathrm{c}^{* *}$ & 12.11 \\
\hline Compulsivity & 49.65 & 11.00 & 47.93 & 11.08 & 53.60 & 9.81 \\
\hline Conduct problems & $26.8 I^{a^{* *+b * * * k}}$ & 8.51 & $30.83^{a^{* *}}$ & 10.33 & $33.53 \mathrm{~b} * * *$ & 10.72 \\
\hline Submissiveness & $35.94^{\mathrm{b}^{* *}}$ & 9.89 & $35.89^{* * *}$ & 9.67 & $42.87^{b^{* *} c^{* * *}}$ & 8.88 \\
\hline Cognitive distortion & $28.39 \mathrm{~b} * * *$ & 9.20 & $29.97 \mathrm{c}^{* * \cdots * k}$ & 9.00 & $41.20^{b^{* * * *}} \mathrm{c}^{* * * *}$ & 13.18 \\
\hline Identity problems & $29.2 \mathrm{I}^{\mathrm{a} * \mathrm{~b}^{* * * *}}$ & 11.02 & $32.76^{a^{*}}$ & $11.97 \mathrm{c}^{* *}$ & $40.40 \mathrm{~b}^{* * * * * * * *}$ & 15.49 \\
\hline Stimulus seeking & 45.15 & 11.72 & 47.87 & $1 \mathrm{I} .57$ & 50.47 & 11.10 \\
\hline Callousness & $31.14 \mathrm{~b}^{*}$ & 8.80 & 32.54 & 10.95 & $36.07^{*}$ & 12.85 \\
\hline Rejection & 44.14 & 10.48 & 42.95 & 10.44 & 46.93 & 11.84 \\
\hline Insecure attachment & $39.87 \mathrm{~b} * * *$ & 13.62 & $43.15^{\mathrm{c}^{* * * *}}$ & 15.07 & $54.80^{\mathrm{b}^{* * * k^{*}} \mathrm{c} * * *}$ & 11.88 \\
\hline Anxiousness & $37.60 \mathrm{~b} * * *$ & 12.63 & $39.33^{\mathrm{c}^{* * * *}}$ & 12.04 & $51.33^{b^{* * * *}} \mathrm{c}^{* * * *}$ & 14.13 \\
\hline Suspiciousness & $28.35 \mathrm{~b} * * *$ & 8.81 & $29.24 \mathrm{c}^{* * * *}$ & 9.32 & $36.20^{\mathrm{b}^{* * * k_{\mathrm{c}}} \mathrm{c} * * * \mathrm{k}}$ & $|1.3|$ \\
\hline Social avoidance & $35.39 \mathrm{~b}^{*}$ & 11.99 & 36.67 & 13.01 & $41.00^{\mathrm{b} *}$ & 11.59 \\
\hline Narcissism & $45.59 b^{*}$ & 12.09 & 47.16 & 12.48 & 51.73 b* & 12.85 \\
\hline Restricted expression & 37.97 & 10.52 & 36.41 & 11.32 & 39.77 & 10.13 \\
\hline Passive aggressivity & $33.2 \mathrm{I}^{\mathrm{a} * \mathrm{~b} * *}$ & 9.79 & $36.29 \mathrm{a}^{*}$ & 11.17 & $39.33^{b^{* * *}}$ & 12.79 \\
\hline Intimacy problems & 27.89 & 8.71 & 28.72 & 10.41 & 30.27 & 9.97 \\
\hline
\end{tabular}

Notes: Procedure: Scheffe multiple comparison test; SD = standard deviation; $\&=$ statistical trend, ${ }^{*} .05-.01 ; * * .01$ to.00I, inclusive; ***.0005; Statistically significant differences between a NSA and SA, b NSA and RSA, and c SA and RSA groups.

$[(\mathrm{OR}=2.0 ; 95 \%$ CI 1.2-3.5)]. In the second model, two narrow traits made significant contributions and had similar effect sizes. Both affective instability $[(\mathrm{OR}=1.1 ; 95 \%$ $\mathrm{CI} 1.04-1.1)]$ and anxiousness $[(\mathrm{OR}=.92 ; 95 \% \mathrm{CI}$ $.88-.95)]$ differentiated between nonattempters and onetime attempters Anxiousness also differentiated between repeated attempters and one-time suicide attempters [(OR $=1.1 ; 95 \%$ CI 1.01-1.1)].

In both models, suicidal ideation and CSA (childhood sexual abuse) had positive associations with suicide attempts. CSA effect size was similar in both models [(OR $=1.5 ; 95 \%$ CI $1.2-1.8)]$. In contrast, suicidal ideation had a greater range of effect sizes (ORs $=4.7-8.4$ ) in the broad than in the narrow personality trait model (ORs = 6.1-6.6). In terms of the quantitative differences, according to our information criteria, the narrow personality trait model $[\mathrm{AIC}=412.878$; $\mathrm{BIC}=468.958]$ performed somewhat better than the one featuring broad traits [AIC $=433.669$; $\mathrm{BIC}=480.403]$.

\section{Discussion}

Up to a half of all suicide attempters, according to some estimates, may have made more than one suicide attempt in their lifetime $[42,43]$. Compared to one-time suicide attempters, repeaters are more likely to complete suicide $[44,6]$. They also have more severe clinical and behav- ioural profiles, including more extensive emotional regulation problems, aggression, impulsivity, cognitive rigidity, and neuroticism $[16,6,45,46]$.

Establishing which personality traits have the potential to differentiate between individuals engaging in suicidal acts of different degrees of severity would help us to identify persons at risk and also to understand the processes underlying the link of personality and nonfatal suicidal behaviours. The present study makes a unique contribution to the field by investigating qualitative and quantitative differences between broad and narrow personality trait correlates of suicide attempts. Our findings suggest that anxiousness and Compulsivity may successfully differentiate between repeated and one-time suicide attempters. Anxiousness and affective instability, on the other hand, may be useful in differentiating between nonattempters and one-time suicide attempters.

\section{Personality trait profiles in repeated and one-time attempters}

Our univariate findings suggest that, relative to one-time attempters and nonattempters, multiple suicide attempters score higher on many of the personality traits measured in this study. A broad personality trait defined as Emotional Dysregulation as well as five of its cognate narrow personality traits, appear to be markers of repeated 


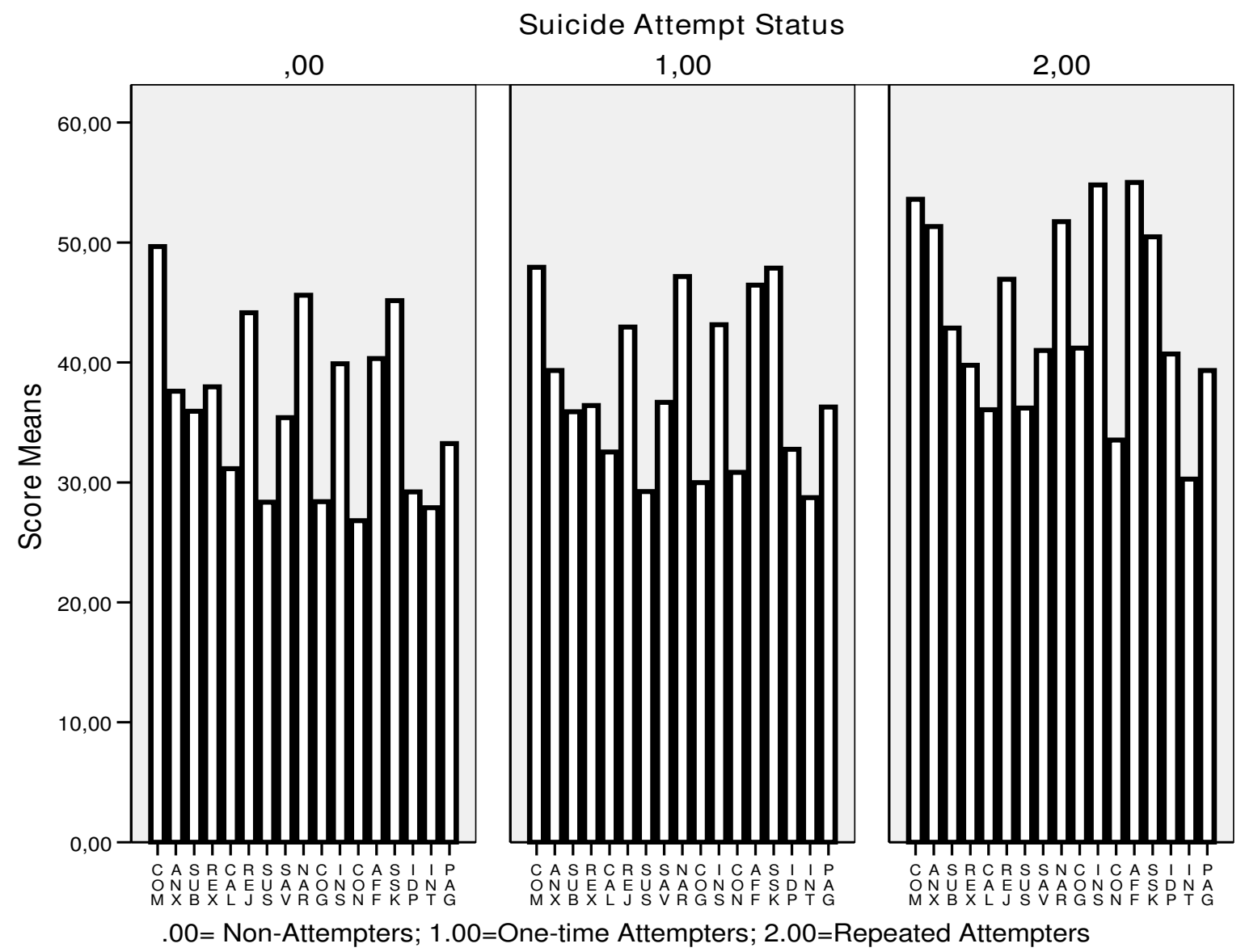

Figure I

Narrow Personality Trait Scores in Nonattempters, One-time and Repeated Attempters. com = compulsivity, anx = anxiousness, sub = submissiveness, rex = restricted expression, cal = callousness, rej $=$ rejection, sus $=$ suspiciousness, nar $=$ narcissism, $\operatorname{cog}=$ cognitive-perceptive dysregulation, ins $=$ insecure attachment, con $=$ conduct problems, aff $=$ affective instability, ssk = stimulus seeking, idp = identity problems, int = intimacy problems, pag $=$ passive aggressivity.

suicide attempts. Two additional traits related to this broad dimension differentiated between all three groups of participants in a dosage-dependent fashion, being the highest among repeated attempters.

Emotional Dysregulation is related, although not identical, to Neuroticism and Harm Avoidance $[9,19,47,48]$. It consists of the shared variance of ten narrow personality traits affecting self-perception (narcisissm, identity problems), interpretation of a situation (cognitive perceptive dysregulation), reaction to perceived stressors (anxiousness, affective instability, passive-aggressivity), and interaction with social environment (submissiveness, insecure attachment, social avoidance, and suspiciousness). Because it affects multiple, and essential, aspects of functioning, it is not surprising that, at least in persons with predisposition to self-harm, Emotional Dysregulation may lead to repeated suicide attempts [16]. More specifically, repetition may be related to one's inability to tolerate and express frustration, on the one hand, and, on the other, to one's perception that a suicide attempt is "an immediate, constantly available, effective recourse at times of crises" [49].

\section{Broad and narrow personality traits as markers of suicide attempt status}

In answer to our main research question - which of two levels of personality traits may be more useful as markers of different subgroups of suicide attempters- we identified both qualitative and quantitative differences. In statistical terms, the model featuring narrow personality traits performed better. Nevertheless, the associated effect sizes were bigger for the broad than for the narrow personality trait correlates. 


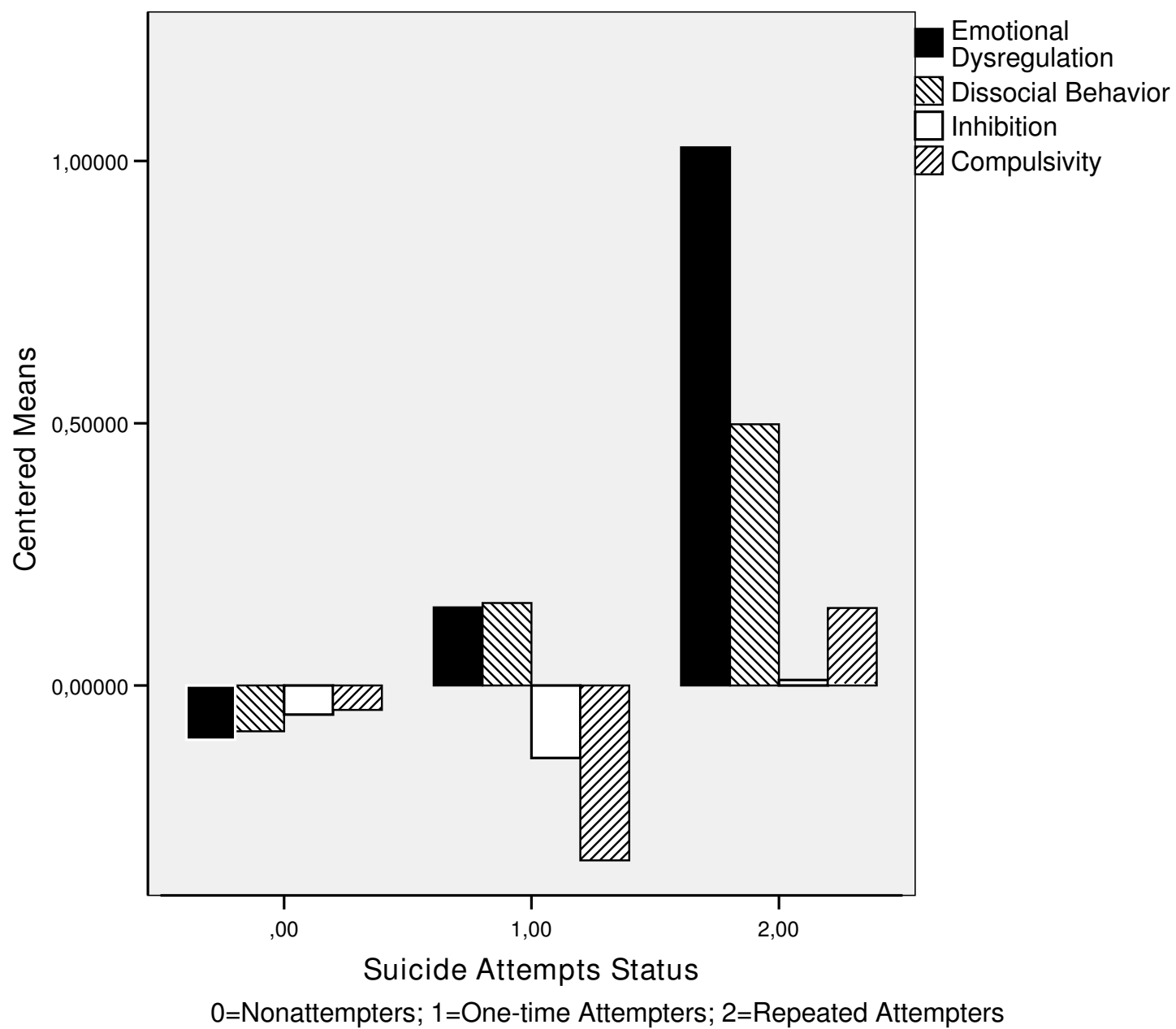

Figure 2

Broad Personality Trait Scores in Nonattempters, One-time and Repeated Attempters.

Concerning qualitative differences, the final, narrow personality trait model included affective instability and anxiousness, components of the broad Emotional Dysregulation factor. The broad personality trait model, on the other hand, featured Compulsivity, factor consist- ing of the shared variance of the narrow traits of rejection and compulsivity. This broad factor is related to obsessivecompulsive personality disorders and borderline symptoms [50,51]. Obsessive-compulsive tendencies - "repetitive unpleasant thoughts and ritualized behaviors" [52]-

Table 2: Suicide attempts and broad personality traits: a multinomial regression model

\begin{tabular}{|c|c|c|c|c|c|c|c|c|c|}
\hline & \multicolumn{3}{|c|}{ Likelihood of RSA vs NSA } & \multicolumn{3}{|c|}{ Likelihood of SA vs NSA } & \multicolumn{3}{|c|}{ Likelihood of RSA vs SA } \\
\hline & $B(S E)$ & $\operatorname{Exp}[\mathrm{B}](95 \% \mathrm{Cl})$ & $P$ & $\mathrm{~B}(\mathrm{SE})$ & $\operatorname{Exp}[\mathrm{B}](95 \% \mathrm{Cl})$ & $P$ & $B(S E)$ & $\operatorname{Exp}[\mathrm{B}](95 \% \mathrm{Cl})$ & $\mathrm{P}$ \\
\hline Childhood mood disorder & $1.23(.62)$ & $3.43(1.02-11.54)$ & .047 & $.19(.51)$ & $1.20(.44-3.30)$ & .720 & $-1.05(.69)$ & $2.85(.74-10.94)$ & .128 \\
\hline Childhood sexual abuse & $.40(.10)$ & $1.49(1.23-1.81)$ & .0005 & $.15(.09)$ & $1.16(.97-1.38)$ & .096 & $.25(.11)$ & $1.29(1.03-1.61)$ & .025 \\
\hline Suicidal ideation (lifetime) & $2.13(.42)$ & $8.39(3.71-18.99)$ & .0005 & $1.54(.20)$ & $4.67(3.18-6.86)$ & .0005 & $.59(.44)$ & $1.80(.75-4.29)$ & .187 \\
\hline Compulsivity & $.47(.25)^{\prime}$ & $1.60(.97-2.62)$ & .063 & $-.23(.15)$ & $.79(.59-1.06)$ & .125 & $.70(.28)$ & $2.01(1.17-3.45)$ & .011 \\
\hline
\end{tabular}

Model fit: $X^{2}{ }_{8}=159.25 \mathrm{p}=.0005 ;$ McFadden $\mathrm{R}^{2}=27.8 \% ; \mathrm{RSA}=$ Repeated suicide attempters $(\mathrm{n}=34) ; \mathrm{SA}=$ one-time suicide attempters $(\mathrm{n}=90)$; NSA $=$ nonattempters $(n=970)$. 
Table 3: Suicide attempts and narrow personality traits: a multinomial regression model

\begin{tabular}{|c|c|c|c|c|c|c|c|c|c|}
\hline & \multicolumn{3}{|c|}{ Likelihood of RSA vs NSA } & \multicolumn{3}{|c|}{ Likelihood of SA vs NSA } & \multicolumn{3}{|c|}{ Likelihood of RSA vs SA } \\
\hline & $\mathrm{B}(\mathrm{SE})$ & $\operatorname{Exp}[B](95 \% \mathrm{Cl})$ & $P$ & $\mathrm{~B}(\mathrm{SE})$ & $\operatorname{Exp}[\mathrm{B}](95 \% \mathrm{Cl})$ & $P$ & $\mathrm{~B}(\mathrm{SE})$ & $\operatorname{Exp}[\mathrm{B}](95 \% \mathrm{Cl})$ & $\mathrm{P}$ \\
\hline Childhood mood disorder & $1.01(.62)$ & $2.75(.815-9.28)$ & .103 & $.19(.52)$ & $1.20(.43-3.36)$ & .723 & $.83(.69)$ & $2.29(.59-8.91)$ & .234 \\
\hline Childhood sexual abuse & $.37(.10)$ & $1.45(1.20-1.77)$ & .0005 & $.11(.09)$ & $1.12(.93-1.33)$ & .230 & $.27(.12)$ & $1.30(1.04-1.64)$ & .023 \\
\hline Suicidal ideation (lifetime) & $1.89(.43)$ & $6.61(2.86-15.27)$ & .0005 & $\mathrm{I} .8 \mathrm{I}(.23)$ & $6.10(3.90-9.54)$ & .0005 & $.08(.46)$ & $1.08(.44-2.68)$ & .863 \\
\hline Anxiousness & $-.01(.03)$ & $.99(.93-1.05)$ & .738 & $-.09(.02)$ & $.92(.88-.95)$ & .0005 & $.08(.03)$ & $1.08(1.01-1.15)$ & .024 \\
\hline Affective instability & $.05(.03)$ & $1.05(.99-1.12)$ & .117 & $.07(.02)$ & $1.08(1.04-1.12)$ & .0005 & $-.02(.03)$ & $.98(.91-1.05)$ & .501 \\
\hline
\end{tabular}

Model fit: $X^{2}{ }_{10}=178.48 p=.0005 ;$ McFadden $R^{2}=31.2 \% ; R S A=$ Repeated suicide attempters $(n=34) ; S A=$ one-time suicide attempters $(n=90)$; NSA $=$ nonattempters $(n=970)$.

have, in turn, been linked to suicide attempts and selfharm, although research on repeated suicide attempts is lacking [53-55]. In addition, repetitive self-harm and lowlethality suicide attempts are one of the main features of borderline personality disorder, possibly associated with impaired decision-making and cognitive rigidity [56]. The latter, along with interpersonal hostility, is one of the main facets of rejection, a trait underlying the Compulsivity factor. All three of these personality constructs have been linked to suicidal tendencies in diverse populations $[57,58,24]$.

Specific, rather than only shared, variance associated with anxiousness and affective instability contributed significantly in the model examining narrow trait correlates of suicide attempts. Interestingly, the effects of these two highly correlated traits $\left(\mathrm{r}^{2}=.70\right)$ were quite distinct. Affective instability levels were significantly higher in one-time suicide attempts than in nonattempters. While previous evidence in individuals who have attempted suicide once is lacking, positive associations of suicide attempts and constructs similar to affective instability have been reported before. For example, emotional instability is a correlate of completed suicide [59] and of borderline personality disorder, a recognized clinical risk factor of suicide attempts [50]. Facets of affective instability, such as irritability, have, furthermore, been found to be relevant in different subpopulations of suicide attempters: males [60], college students [61], and depressed patients [62].

Anxiety had a dual role: it was related to a lower likelihood of one-time suicide attempts but a higher likelihood of repeated suicide attempts. The second scenario -that anxiousness is more likely to be higher in repeated than in first-time suicide attempters -is in line with the finding that childhood anxiety predisposes to multiple suicide attempts [63]. Other studies have, for the most part, however, focused on suicide attempters as a group, without distinguishing between one-time and repeated attempters, typically finding it to be higher in suicide attempters of different age and clinical histories $[6,64,65]$.
The first finding - that anxiousness may be associated with a somewhat lower likelihood of attempting suicide once rather than never- is not easily explained, although a similar scenario has been reported before. Low anxiety in different age groups increased the risk of suicide death $[59,66]$. Alternatively, this negative association may be related to the characteristics of the suicide attempt such as its timing. If recent, suicide attempts, for example, may have alleviated anxiousness [49]. Cathartic effects - a decrease in negative feelings following a suicide attempt $[67,68]$-have been observed for several pathological personality traits [49]. Personal interpretation and definition of "suicide attempts" may have also differed between selfreported one-time suicide attempters and nonattempters. Additionally, the relationship of anxiousness and suicide attempts may indeed be bi- or multimodal and differ across anxiety levels. Namely, slightly elevated anxiousness may not be as incapacitating as its excessively high levels and is possibly more conducive to help-seeking behaviors or better management of suicidal thoughts before they escalate into suicidal acts. Alternatively, an unidentified moderator may be involved $[69,70]$. Gender and sociodemographic factors are possible, although, judging by the evidence to date, unlikely candidates [71]. Our own gender-based moderating analyses were precluded by a small number of males among repeaters.

In conclusion, significant personality correlates in our two models are associated with two different personality dimensions: Compulsivity and Emotional Dysregulation. One of the explanations for this intriguing finding may be related to the fact that narrow and broad personality traits are not directly comparable as they are not structurally equivalent. As mentioned earlier, broad traits, such as Compulsivity, consist only of shared variance of their associated narrow traits. In contrast, the shared variance of anxiousness and affective instability, two of the narrow personality traits contributing to Emotional Dysregulation and to our second model, was controlled for in our regressions. This difference, however, does not invalidate their relevance nor previous support for the involvement 
of several different personality constructs in suicidal behaviors.

\section{Conclusion}

Personality traits' influence on health outcomes is multidimensional and possibly mediated by socioenvironmental factors, health-related behaviours, and a number of psychophysiological processes [72,73]. In terms of the suicide attempts of different severity, our data demonstrated that both emotional and cognitive dysregulation may be involved.

Whether narrow or broad personality traits may be more optimal in differentiating between multiple and one-time suicide attempters depends on the specific research objective. Findings associated with narrow traits may be easier to interpret and link to existing known sociobiological theories. Larger effect sizes associated with broad traits may be better suited to objectives with a more clinical focus. Nevertheless, the extent to which these and similar conclusions are contingent on differences in sample characteristics, temporal changes, and statistical approaches requires further research consideration.

Most measures were retrospective and subject to recall bias. Psychometric properties of instruments assessing suicidal intent and suicidal ideation were not as high as expected, possibly due to translation problems. Nevertheless, our assessment of suicidality relied on a number of other measures in addition to these two scales.

We were also unable to exclude non-specific, cohort effects resulting from repeated assessments. We are, moreover, unsure of the extent to which the responses on personality measures were influenced by current states. Finally, our findings are based on a relatively culturallyhomogeneous community sample and therefore have limited generalizibility to other cultural groups and to clinical populations.

\section{Competing interests}

The author(s) declare that they have no competing interests.

\section{Authors' contributions}

JB conceived of the study and statistical strategy, conducted data analysis and data interpretation, and drafted the manuscript.

RT coordinated and planned the psychosocial and clinical assessments and subject recruitment.

FV contributed to the planning of the psychosocial and clinical assessments and subject recruitment and provided input on data interpretation and editorial help.
MH contributed to the planning of the psychosocial and clinical assessments and subject recruitment.

JP provided editorial help and input on data interpretation.

GT supervised the study, provided feedback on the analyses and interpretation, and provided editorial help.

All authors read and approved the final manuscript.

\section{References}

I. Brezo J, Paris J, Turecki G: Personality traits as correlates of suicidal ideation, suicide attempts, and suicide completions: a systematic review. Acta Psychiatr Scand 2006, I I 3: I80-206.

2. Youssef G, Plancherel B, Laget J, Corcos M, Flament MF, Halfon O: Personality trait risk factors for attempted suicide among young women with eating disorders. Eur Psychiatry 2004, 19:131-139.

3. Fergusson DM, Beautrais AL, Horwood LJ: Vulnerability and resiliency to suicidal behaviours in young people. Psychol Med 2003, 33:61-73.

4. Turecki G: Dissecting the suicide phenotype: the role of impulsive-aggressive behaviours. J Psychiatry Neurosci 2005, 30:398-408.

5. Baud P: Personality traits as intermediary phenotypes in suicidal behavior: genetic issues. Am J Med Genet C Semin Med Genet 2005, I 33:34-42.

6. Stein D, Apter A, Ratzoni G, Har-Even D, Avidan G: Association between multiple suicide attempts and negative affects in adolescents. J Am Acad Child Adolesc Psychiatry 1998, 37:488-494.

7. Krueger RF, Caspi A, Moffitt TE: Epidemiological personology: the unifying role of personality in population-based research on problem behaviors I. J Pers 2000, 68:967-998.

8. McCrae RR, Costa PT: Toward a new generation of personality theories: Theoretical contexts for the five-factor model. In The five-factor model of personality; Theoretical perspectives Edited by: Wiggins JS. New York, Guilford Press; 1996:5I-57.

9. Cloninger CR: A systematic method for clinical description and classification of personality variants. A proposal. Arch Gen Psychiatry 1987, 44:573-588.

10. Jang KL, McCrae RR, Angleitner A, Riemann R, Livesley WJ: Heritability of facet-level traits in a cross-cultural twin sample: support for a hierarchical model of personality. J Pers Soc Psychol 1998, 74: I556-| 565.

II. Eysenck JJ: Dimensions of personality London, Routledge \& Kegan Paul; 1947.

12. Paunonen SV, Ashton MC: Big five factors and facets and the prediction of behavior. J Pers Soc Psychol 2001, 81:524-539.

13. Shiner R: Methods for assessing personality in children and parents in developmental epidemiologic studies. Instruments for assessing personality in children and adolescents.: 2005; Montreal. 2005.

14. Maris RW, Berman AL, Maltsberger JT, Yufit RI: Assessment and Prediction of Suicide. New York., Guilford Press; 1992.

15. Gould MS, Wallenstein S, Kleinman MH, O'Carroll P, Mercy J: Suicide clusters: an examination of age-specific effects. Am J Public Health 1990, 80:211-2I2.

16. Rudd MD, Joiner T, Rajab $M H$ : Relationships among suicide ideators, attempters, and multiple attempters in a young-adult sample. J Abnorm Psychol 1996, I 05:54I-550.

17. Forman EM, Berk MS, Henriques GR, Brown GK, Beck AT: History of multiple suicide attempts as a behavioral marker of severe psychopathology. Am J Psychiatry 2004, I 6 I :437-443.

18. Brezo J, Paris J, Tremblay R, Vitaro F, Zoccolillo M, Hebert M, Turecki $\mathrm{G}$ : Personality traits as correlates of suicide attempts and suicidal ideation in young adults. Psychol Med 2006, 36: I91-202.

19. Livesley WJ, Jang KL, Vernon PA: Phenotypic and genetic structure of traits delineating personality disorder. Archives of General Psychiatry 1998, 55:941-948.

20. Brezo J, Paris J, Tremblay R, Vitaro F, Turecki G: DAPP-BQ: Factor Structure in French Canadians. J Personal Disord 2008. 
21. Fergusson DM, Woodward LJ, Horwood LJ: Risk factors and life processes associated with the onset of suicidal behaviour during adolescence and early adulthood. Psychol Med 2000, 30:23-39.

22. Roy A: Characteristics of drug addicts who attempt suicide. Psychiatry Res 2003, I 21:99-103.

23. Roy A: Distal risk factors for suicidal behavior in alcoholics: replications and new findings. J Affect Disord 2003, 77:267-27I.

24. Benjaminsen S, Krarup G, Lauritsen R: Personality, parental rearing behaviour and parental loss in attempted suicide: a comparative study. Acta Psychiatr Scand 1990, 82:389-397.

25. Janowsky DS, Morter S, Hong L: Relationship of Myers Briggs type indicator personality characteristics to suicidality in affective disorder patients. J Psychiatr Res 2002, 36:33-39.

26. Tremblay RE, Schaal B: Physically aggressive boys from age 6 to 12 years. Their biopsychosocial status at puberty. Ann NY Acad Sci 1996, 794: 192-207.

27. Cote S, Tremblay RE, Nagin DS, Zoccolillo M, Vitaro F: Childhood behavioral profiles leading to adolescent conduct disorder: risk trajectories for boys and girls I. J Am Acad Child Adolesc Psychiatry 2002, 41:1086-1094.

28. Straus MA: Measuring intrafamily conflict and violence: The Conflict Tactics Scales. J Marriage Fam 1979, 41:75-88.

29. Straus MA, Hamby SL, Boney-McCoy S, Sugarman DB: The revised conflict tactics scales (CTS2). Development and preliminary psychometric data. Journal of Family Issues 1996, 17:283-316.

30. D F: Sexually victimized children New York, Free Press; 1979.

31. Felitti VJ, Anda RF, Nordenberg D, Williamson DF, Spitz AM, Edwards V, Koss MP, Marks JS: Relationship of childhood abuse and household dysfunction to many of the leading causes of death in adults. The Adverse Childhood Experiences (ACE) study. American Journal of Preventive Medicine 1998, 14:245-248.

32. Horney J: Crime and the criminal events perspective. In The Process and Structure of Crime: Criminal Events and Crime Analysis Edited by: Meier RF, Kennedy LW and Sacco VF. New Brunswick, NJ, Transaction Publishing; 2001:141-167.

33. Breton J, Tousignant M, Bergeron L, Berthiaume C: Informant-specific correlates of suicidal behavior in a community survey of 12- to 14-year-olds. J Am Acad Child Adolesc Psychiatry 2002, 41:723-730.

34. Steiger H, Koerner N, Engelberg MJ, Israel M, Ng Ying Kin NM, Young $\mathrm{SN}$ : Self-destructiveness and serotonin function in bulimia nervosa. Psychiatry Res 200I, 103:15-26.

35. Barratt E: Impulsive subtraits: arousal and information processing. In Motivation, Emotion, and Personality Edited by: Spence JT and Izard CE. New York, Elsevier; 1985: I 37-I 46.

36. Heila $\mathrm{H}$, Isometsa ET, Henriksson MM, Heikkinen ME, Marttunen MJ, Lonnqvist JK: Suicide and schizophrenia: a nationwide psychological autopsy study on age- and sex-specific clinical characteristics of 92 suicide victims with schizophrenia. $\mathrm{Am}$ Psychiatry 1997, 154: I 235- 1242.

37. deMan AF, Leduc CP, Labreche-Authier L: A French-Canadian scale for suicidal ideation for use with adolescents. Soc Behav Pers 1994, 22:26I-266.

38. Beck AT, Brown GK, Steer RA: Psychometric characteristics of the Scale for Suicide Ideation with psychiatric outpatients. Behav Res Ther 1997, 35:1039-1046.

39. Beck RW, Morris JB, Beck AT: Cross-validation of the Suicidal Intent Scale. Psychol Rep 1974, 34:445-446.

40. Turner RJ: Social support: conceptualization, measurement, and implications for mental health. Research in Community and Mental Health 1983, 3:67- II I.

41. Hosmer DW, Lemeshow S: Applied logistic regression New York, Wiley \& Sons; 2000.

42. Sakinofsky I, Roberts RS: Why parasuicides repeat despite problem resolution. Br J Psychiatry 1990, 156:399-405.

43. Wang AG, Nielsen B, Bille-Brahe $U$, Hansen W, Kolmos L: Attempted suicide in Denmark. III. Assessment of repeated suicidal behaviour. Acta Psychiatr Scand 1985, 72:389-394.

44. Kotila L, Lonnqvist J: Suicide and violent death among adolescent suicide attempters. Acta Psychiatr Scand 1989, 79:453-459.

45. van HC: Suicide, serotonin, and the brain. Crisis 200I, 22:66-70

46. Hawton A, Osborn M, O'Grady J, Cole D: Classification of adolescents who take overdoses. Br J Psychiatry 1982, I 40:|24-|3|.
47. Costa PTJ, McCrae RR: Domains and facets: hierarchical personality assessment using the revised NEO personality inventory. J Pers Assess 1995, 64:21-50.

48. Eysenck HJ, Eysenck MW: Personality and Individual Differences: A Natural science Approach New York, Plenum Publishing Corp; 1985.

49. Sarfati $Y$, Bouchaud B, Hardy-Bayle MC: Cathartic effect of suicide attempts not limited to depression: a short-term prospective study after deliberate self-poisoning. Crisis 2003, 24:73-78.

50. Bagge CL, Trull TJ: DAPP-BQ: factor structure and relations to personality disorder symptoms in a non-clinical sample. J Personal Disord 2003, 17:19-32.

5I. Pukrop R, Gentil I, Steinbring I, Steinmeyer E: Factorial structure of the German version of the dimensional assessment of personality pathology-basic questionnaire in clinical and nonclinical samples. J Personal Disord 200I, I 5:450-456.

52. Brune M: The evolutionary psychology of obsessive-compulsive disorder: the role of cognitive metarepresentation. Perspect Biol Med 2006, 49:317-329.

53. Abdel-Khalek A, Lester D: Can personality predict suicidality? A study in two cultures. Int / Soc Psychiatry 2002, 48:23I-239.

54. Ucok A, Tukel R, Ozgen G, Saylan M, Uzuner G: [Frequency of obsessive compulsive symptoms and disorder in patients with schizophrenia: importence for prognosis]. Encephale 2006, 32:4I-44.

55. Scahill L, McDougle CJ, Williams SK, Dimitropoulos A, Aman MG, McCracken JT, Tierney E, Arnold LE, Cronin P, Grados M, al. : Children's Yale-Brown Obsessive Compulsive Scale modified for pervasive developmental disorders. J Am Acad Child Adolesc Psychiatry 2006, 45: I I 4-II23.

56. LeGris J, van RR: The neuropsychological correlates of borderline personality disorder and suicidal behaviour. Can J Psychiatry 2006, 5 I: $|3|-\mid 42$

57. Baumeister RF: Suicide as escape from self. Psychol Rev 1990, 97:90-II3.

58. Kaslow NJ, Price AW, Wyckoff S, Bender GM, Sherry A, Young S, Scholl L, Millington U V, Rashid A, Jackson EB, Bethea K: Person factors associated with suicidal behavior among African American women and men. Cultur Divers Ethnic Minor Psychol 2004, 10:5-22.

59. Neeleman J, Wessely S, Wadsworth M: Predictors of suicide, accidental death, and premature natural death in a general-population birth cohort. Lancet 1998, 35 I:93-97.

60. Stalenheim EG: Relationships between attempted suicide, temperamental vulnerability, and violent criminality in a Swedish forensic psychiatric population. Eur Psychiatry 200I, 16:386-394.

61. Lester D: Suicidal preoccupation and dysthymia in college students. Psychol Rep 1987, 61:762.

62. Pendse $B$, Westrin A, Engstrom G: Temperament traits in seasonal affective disorder, suicide attempters with non-seasonal major depression and healthy controls. J Affect Disord 1999, 54:55-65.

63. Rudd MD, Joiner TE Jr., Rumzek $\mathrm{H}$ : Childhood diagnoses and later risk for multiple suicide attempts. Suicide Life Threat Behav 2004, 34: I I3-125

64. Goldston DB, Daniel S, Reboussin DM, Kelley A, levers C, Brunstetter R: First-time suicide attempters, repeat attempters, and previous attempters on an adolescent inpatient psychiatry unit. J Am Acad Child Adolesc Psychiatry 1996, 35:631-639.

65. Seidlitz L, Conwell Y, Duberstein P, Cox C, Denning D: Emotion traits in older suicide attempters and non-attempters. J Affect Disord 200I, 66:123-131.

66. Dumais A, Lesage AD, Alda M, Rouleau G, Dumont M, Chawky N, Roy M, Mann J], Benkelfat C, Turecki G: Risk factors for suicide completion in major depression: a case-control study of impulsive and aggressive behaviors in men. Am J Psychiatry 2005, 162:2116-2124.

67. Walker RL, Joiner TE Jr., Rudd MD: The course of post-crisis suicidal symptoms: how and for whom is suicide "cathartic"? Suicide Life Threat Behav 200I, 31:I44-I52.

68. Davis AT: Short-term course of depression following attempted suicide: a preliminary report. Acta Psychiatr Scand 1990, 81:345-351.

69. Mean M, Righini NC, Narring F, Jeannin A, Michaud PA: Substance use and suicidal conduct: a study of adolescents hospitalized for suicide attempt and ideation. Acta Paediatr 2005, 94:952-959. 
70. Costa PT Jr., Terracciano A, McCrae RR: Gender differences in personality traits across cultures: robust and surprising findings I. J Pers Soc Psychol 200I, 81 :322-33I.

7I. Roy A: Relationship of childhood trauma to age of first suicide attempt and number of attempts in substance dependent patients. Acta Psychiatr Scand 2004, 109:121-125.

72. Adler N, Matthews K: Health psychology: why do some people get sick and some stay well? Annu Rev Psychol 1994, 45:229-259.

73. Bogg T, Roberts BW: Conscientiousness and health-related behaviors: a meta-analysis of the leading behavioral contributors to mortality. Psychol Bull 2004, 130:887-919.

\section{Pre-publication history}

The pre-publication history for this paper can be accessed here:

http://www.biomedcentral.com/1471-244X/8/15/pre pub

Publish with Biomed Central and every scientist can read your work free of charge

"BioMed Central will be the most significant development for disseminating the results of biomedical research in our lifetime. "

Sir Paul Nurse, Cancer Research UK

Your research papers will be:

- available free of charge to the entire biomedical community

- peer reviewed and published immediately upon acceptance

- cited in PubMed and archived on PubMed Central

- yours - you keep the copyright

Submit your manuscript here:

http://www.biomedcentral.com/info/publishing_adv.asp
BioMedcentral 